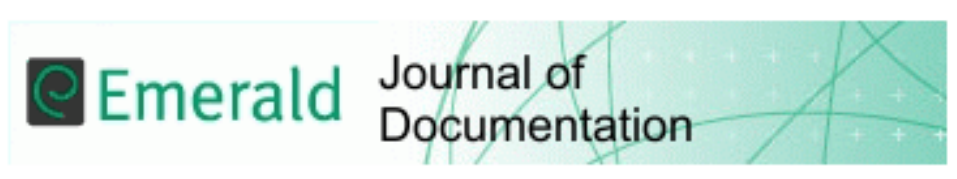

\title{
Bringing order or creating exclusion: systems for managing disability in a university
}

\begin{tabular}{|r|l|}
\hline Journal: & Journal of Documentation \\
\hline Manuscript ID & JD-12-2020-0208.R3 \\
\hline Manuscript Type: & Article \\
\hline Keywords: & $\begin{array}{l}\text { Classification schemes, Students, Universities, Disability, Marginalisation, } \\
\text { Power }\end{array}$ \\
\hline
\end{tabular}

\section{SCHOLARONE \\ Manuscripts}


Bringing order or creating exclusion: systems for managing disability in a university

Hilary Yerbury

Simon Darcy

Nina Burridge

Barbara Almond

University of Technology Sydney, Sydney, Australia

Abstract
Purpose

Classification schemes make things happen. The Australian Disability Discrimination Act, which derives its classification system from the World Health Organisation's International Classification of Functioning, Disability and Health (ICF), legislates for adjustments to support the inclusion of people with disability. This study explores how students with disability enrolled in a university experience the systems intended to facilitate their studying "on the same basis" as students without disability.

\section{Methodology}

Through an online questionnaire and interviews comprising open and closed questions made available to students registered with the Disability Services unit of a university and follow-up interviews with a small number of students, students' views of their own disability, and effects on their participation in learning were gathered, alongside reports of their experiences of seeking accommodations. Interview data and responses to open-ended questions were analysed using a priori and emergent coding.

\section{Findings}

The findings demonstrate that students are aware of the workings of the classification scheme and that most accept them. However, some students put themselves outside of the scheme, often as a way to exercise autonomy or to assert their 'ability', while others are excluded from it by the decisions of academic staff. Thus, the principles of fairness and equity enshrined in legislation and policy are weakened.

\section{Originality}

Through the voices of students with disability, it is apparent that, even though a student's classification according to the DDA and associated university policy remains constant, the outcomes of the workings of the scheme may reveal inconsistencies, emerging from the complexity of bureaucracy, processes and the exercises of power.

Keywords: classification; disability; university; students; marginalization, power

\section{Introduction}

Classification schemes are fundamental to the organisation of knowledge. Along with controlled vocabularies and taxonomies they have been central to most information practices in organisations as well as in the wider community. Organisations establish systems of various kinds to manage data about their core business and to gather information about their staff and clients or customers. Information about products, artefacts or specialist knowledge and expertise may be the subject of 
discussion and debate as societal perceptions shift. To the extent that classification schemes are applied to people in an organisational setting, they tend to use a surrogate such as job title or language spoken to stand for the person and there is an assumption that such classifications use categories that appropriately encompass characteristics of the people about whom information is collected. This study seeks to answer the question: what do the experiences and actions of students with disability reveal about the classifications and processes used in that university to deem that a student has a disability and to identify appropriate strategies and mechanisms of support for their learning? It does this through an exploration of the experiences and actions of students with disability (SwD) studying in a large metropolitan university in Australia, regarding their own disability, the effects of their impairment on their participation in learning and the impacts of accommodations or adjustments, made under Australia's Disability Discrimination Act 1992 (DDA) and the Australian Vice Chancellors' Committee (AVCC) Guidelines relating to Students with a Disability. Such an investigation will not only give a voice to those to whom the classification system is applied, but through those voices show how a classification scheme may be applied idiosyncratically and have unintended consequences. The study furthers challenges made to classification schemes which are applied in social contexts.

\section{Background}

The World Health Organisation's International Classification of Functioning, Disability and Health, known more commonly as ICF, (World Health Organization, 1980, 2001, 2002) underpins the approach to identifying disability and providing services and support throughout the world. National data standards, including the Australian Bureau of Statistics' Disability, Ageing and Carers Survey (Australian Bureau of Statistics, 2019) deriving from the ICF, facilitate a standardised approach to data collection and to the development of national and local policies. These sources, ICF and ABS, influenced the definitions of disability included within Australia's Disability Discrimination Act 1992 (DDA), which covers aspects of life including education, employment, access to buildings, engagement in community activities and sport, and so on. The ICF started as a classification based entirely on a medical model of disability, identifying functions and structures of the body where problems, including disease, may occur, and taking a deficit approach to classification of impairments. The 2001 revision of the ICF attempted to broaden the basis of the classification scheme and build systematically on earlier attempts to include a social dimension to disability (Hogan, 2019), including a section on activities and participation and another on environmental factors. This attempt to incorporate a sense of the whole person was not without its critics who argued that it did little to broach the definitional differences between impairment and disability (Bickenbach et al., 1999; Leonardi et al., 2006). The section on activities and participation proposes the kinds of activities an individual might engage in which would be affected by a given disability.

Many government and institutional practices in Australia are based on the DDA and therefore on the ICF. More recently, they have been further supported by the articles in the UN Convention on the Rights of Persons with Disabilities (2006). In the university sector, the Australian Vice Chancellors' Committee (AVCC) Guidelines relating to Students with a Disability uses the DDA as the foundation for the provision of support and services to students through "reasonable accommodations". In other settings including the workplace, the term adjustments may be more commonly used. These are processes and procedures, including access to information communication technologies (ICT), which would enable SwD to study "on the same basis" as a student without disability. Access to inclusive IT and assistive technology has been recognised as an important consideration in education and employment settings for people with disability (Heath and Babu, 2017). With Universities Australia, (formerly the AVCC) adopting the provision of these procedures and access to ICT, they are akin to educators creating a level playing field for a SwD. Both the DDA and the AVCC Guidelines are recognised as being fundamental to the policies developed in Australian universities, relevant to SwD. Thus, at the point of enrolment in a university, students are asked to identify their disability from a 
check list. This helps to provide national statistics, and to inform national processes of policy development. Once admitted to a university, a SwD must apply for registration with the relevant service within the university. This involves providing documentation of their disability from a recognised medical practitioner, specialist, or psychologist/psychiatrist in the case of psychosocial disability. This process follows what is inherent in the WHO ICF and its associated implementation documents, and it links the classification scheme and the policies and legislation that derive from it with the individual.

\section{Administrative and Legal Frameworks}

This section will briefly set out the structure of the ICF, key definitions from the DDA and the parts of the AVCC Guidelines relating to Students with a Disability relevant to this study. The latter provides the classificatory and administrative frameworks within which universities provide SwD opportunities for learning "on the same basis" as students without disability.

The ICF starts with the broad Health Condition (disorder/disease) and contains five key sections: 1. the body and its functions, the body and its structures; 2. Activities; 3. Participation; 4. Environmental factors; and 5. Personal Factors. Activities and Participation are brought together as a key domain in the classification scheme, and demonstrating the importance of education, the first item listed is Learning and Applying Knowledge. Others include communication, self-care, interpersonal interactions and relationships. Environmental factors do include the natural environment, but also information communication technology as well as attitudes, and services, systems and policies. The document setting out the workings of the classification scheme, including its emphasis on limitations in activities and participation, becomes important to students as its structure is used as a template for them to make the case for their disability and its impact on their everyday lives and on their capacity to complete the requirements of their degree in particular.

The Disability Discrimination Act 1992 (DDA) sets out definitions accepted in the formulation of policies and services in the university sector. Thus, "disability, in relation to a person, means: (a) total or partial loss of the person's bodily or mental functions; or (b) total or partial loss of a part of the body; or (c) the presence in the body of organisms causing disease or illness; or (d) the presence in the body of organisms capable of causing disease or illness; or (e) the malfunction, malformation or disfigurement of a part of the person's body; or (f) a disorder or malfunction that results in the person learning differently from a person without the disorder or malfunction; or $(\mathrm{g})$ a disorder, illness or disease that affects a person's thought processes, perception of reality, emotions or judgment or that results in disturbed behaviour". Time is important in the interpretation of this first part of the definition, so that the definition of disability "includes a disability that: (h) presently exists; or (i) previously existed but no longer exists; or (j) may exist in the future; or (k) is imputed to a person".

This extensive list of disability with its emphasis on deficits mimics the ICF. It also shows how a classification scheme focussing on structures and functions of the body becomes intrinsically related to the person. So that discrimination should not occur, an important definition is of the notion "on the same basis". Under this rubric, "A person with a disability is able to participate in courses or programs provided by an educational institution, and use the facilities and services provided by it, on the same basis as a student without a disability if the person has opportunities and choices in the courses or programs and in the use of the facilities and services that are comparable with those offered to other students without disabilities". With the introduction of the sense of justice and fairness, the person with disability has been brought into the system.

The Australian Vice Chancellors' Committee (2006) Guidelines relating to Students with a Disability, noting on the first page that universities are subject to the DDA, are based on two principles: the upholding of academic standards and the provision of the opportunity for SwD to realise their academic and social potential and participate in university life. Section $4 \mathrm{~B}$ of this document, on 
course delivery and assessment, presents key objectives to be implemented into the policies and practices of each university. Among these are that "Reasonable adjustments are made to delivery and assessment methods to accommodate the needs of individual students without compromising the standards or essential components of programs" that "SwD are encouraged to discuss their learning and support needs directly with teaching staff who are resourced to respond appropriately to these requests" and that "The information access and assistive technology needs of SwD are accommodated in learning and assessment tasks".

The administrative practices which govern $\mathrm{SwD}$ and their learning derive from these documents and bring others into the processes. Students are required to apply to be recognised as having disability, completing a process that parallels the structure of the ICF described above, with supporting documentation from medical experts, so that others can determine what accommodations or supports meet their requirements within the structure of the university policy and the practices of staff responsible for the delivery of learning opportunities. While the framework is set in place, the way that it is implemented varies from educational organisation and in this case university to university.

\section{Classifying Students with Disability}

Classification schemes have real world consequences, and when they are applied to people, even indirectly, they have the effect of linking people to the beliefs and assumptions that underpin the classification scheme (Bowker and Star, 1999, p.319), of making distinctions that separate people (Said, 1979) and exercising power, separating the acceptable from the undesirable Foucault (1977). They impose social order (Bowker and Star 2000, p. 147), facilitating a range of practices, from legal and administrative systems, to specialist systems such as health systems, as well as being fundamental to many fields of scholarship (cf Altman 2001).

Classification schemes are bound by the times and circumstances of their development (Olson, 2010) and these contextual factors are likely to lead to criticism. For example, there have been many criticisms of Dewey Decimal Classification, commonly used to organise library collections, because of its nineteenth century view of the world of knowledge and the social values inherent in it (Wiegand, 1996; Mai 2010; Hajibayova, L and Buente, W, 2017). The taxonomy of Linnaeus is criticised for not taking into account local knowledge systems, even though this is not what it set out to do (Cooper, 2007). The WHO ICF began as a medical model and has attracted its critics. For Darcy and Buhalis (2011), the criticism stems from the ICF's focus on a medical model of disability, rather than the social model which is dominant in the conceptual field. The system has also been criticised because, applied to people, it has the effect of setting up systems which identify deviance from a norm (Campbell, 2019). Hahn critiqued the medical model, because it "requires patients to surrender their autonomy to professional direction" (Hahn, 1985). Hammell, writing at a time when there had been a strong emphasis on the ethical issues involved in speaking for others, noted that the perspectives of disabled people are rarely included in discussions of professional and scholarly experts (Hammell, 2004). Ten years later, in a review of the literature that focussed on the voice of students with disability in higher education, Lane found only 41 studies published between 1996 and 2013, half of which appeared in a single journal, Disability and Society (Lane, 2014).

Classification schemes often embed taken for granted standards. Fredriksson Franzén (2016) demonstrated how in western urbanised living, people take for granted that fruit and vegetables purchased from a supermarket will not only be nutritious but will be pleasing to the eye; fruit and vegetables that do not conform to this standard are deemed ugly, and hence undesirable, so that particular actions are required for this 'ugly' produce to find a place in supermarkets. Applied to people, this approach raises issues. First is the issue of labelling. The phrase 'disabled person' is not widely used in scholarship in Australia, because it is regarded as defining the person by their attribute rather their humanity (Harpur, 2012, p. 327), so that the phrase "person with disability" was to be preferred. And yet in a research report supporting the current Australian Royal Commission into violence, abuse, neglect and exploitation of people with disability, it was noted (Clifton 2020, p.18) 
that the very phrase preferred in Australia, the "person-first language ... implicitly takes disability as a negative construct" and that cultural and identity theorists are reclaiming the label 'disabled', seeing it as a marker of power and source of pride. However, in the context of higher education, students may not want to take this stance and may not want to be labelled "with disability" by others; to avoid this labelling, they may choose not to access the programs and services available to support them in their learning (Grimes et al., 2019). In this context, disability remains hidden, because of the stigma that students perceive they will suffer (Grimes et al., 2017; Beauchamp-Pryor 2012; Blockmans, 2015; Denhart, 2008; Grimes et al., 2019.)

A second issue is the taken-for-granted standard, in western societies, of ableism (Campbell (2019). In her influential work focussing on what it means to be able rather than disabled, Campbell notes (2019) that the ICF is based on assumptions that disability is a deviance from the norm and therefore cast as undesirable. She further demonstrates how an essential aspect of the desirable condition of 'normality' is stability, and that in recognition that disability may not be an incurable state, permanent or stable, categories related to temporary and intermittent conditions are created. However, these time spans are foreseeable; they are not related to the "cripped time" that people with disability may experience. "Cripped time can be staggered, frenzied, coded, meandering and be the distance between two events", according to Campbell, (2012, p.226). Cripped time is time over which an individual may have little control.

Classification systems such as those surrounding people with disability create categories that can be used in a strategically essentialist way to obtain certain kinds of benefits, including access to goods including funding (Peruzzo, 2020), services (Garsten and Jacobsson, 2013) and legal protections (Campbell, 2008). In turn, these systems may be enforceable by law (cf Bowker and Star 2000, p. 150); the rights-based approach emerging after the ratification by states of the United Nations Convention on the Rights of Persons with Disabilities (CRPD) from 2008 (Waddington and Priestley 2021) has added a layer of obligations at the legal and policy levels.

Within organisations, systems of classification are instrumental in making things happen, what Bowker and Star refer to (2000, p. 148-149) as "do[ing] some kind of work". In the context of students at university, the system does two kinds of work - it endorses the student as disabled and it sets out the framework for reasonable adjustment. As Bowker and Star pointed out, a classification scheme applied to people, especially in their everyday lives, can have significant implications for exercises of power. In the context of people with disability seeking support, the very act of filling in a form, answering questions or ticking boxes is an exercise in 'people production' (Barfoed, 2019) or making an individual 'legible' through identifying desirable traits (Garsten and Jacobsson, 2013), can be seen as an exercise of power over them.

Thus, in the context of the university and the processes of seeking accommodations to support learning, students are shaped and constructed as having disability (Holstein, 1992) and that construction becomes public (AVCC Guidelines). The impact of the WHO ICF on the policies, guidelines and procedures which affect the seeking of accommodations influences decisions made about the learning opportunities of students. The pervasiveness of impact of this framework is such that Gabel and Miskovic (2014) were able to identify that the institutional discourses of disability in higher education have been framed around what they call an architecture of containment. This Foucauldian concept has been reframed by Clouder et al. as a "tidy way" to deal with disability. In the context of universities making decisions around accommodations for $\mathrm{SwD}$, the students and their disability have been "categorised and processed" (2016, p.17), thus ensuring that their individual situations have been regularised, brought into conformity with a norm.

Many studies have found that students are often reluctant to be constructed through the application processes and are unwilling to disclose their disability; there may be a variety of reasons, but a common reason is because they want to avoid stigmatisation (e.g. Blockmans, 2015; Denhart, 2008; 
Grimes et al., 2019). Staff in a university, similarly, may be unwilling to disclose their disability, in part because of their concerns with discrimination and bullying (Dali, 2018). The consequence of such a decision is that students and staff can maintain a sense of their own autonomy, exercising the freedom to take up a position of being disabled or not (Peruzzo, 2020, p. 4) but they forfeit the services and support they may have had a right to.

This review of the literature has demonstrated that key questions posed by Bowker and Star in 2000 (p. 148) remain important in the context of systems that classify people. It has shown that the work that these systems do in universities, for $\mathrm{SwD}$, can be construed in various ways: as legally protecting rights, as establishing an administrative framework for managing anomalous cases, as constructing an identity, among other activities. It has also shown that the work is done by the $\mathrm{SwD}$, by the case manager who oversees the filling of the forms and application process and by the academic staff members who decide on the granting of the request and implement the change in learning or assessment practices. Further it has shown that there continue to be "cases that don't fit". The review has also shown that while the social model of disability may be more widely acknowledged in research and in policy development, the voices of people with disability have still not contributed significantly to policy development (Beauchamp-Pryor, 2012). This study explores the question of the work that the classification system inherent in the university practices based on the Australian Disability Discrimination Act, does in supporting their learning, from the voices of the students. Its starting point, the experiences that students report on the categorisation and processing of themselves, maintains a focus on the workings of the classification system itself. This study seeks to augment the work of Bowker and Star $(1999,2000)$, by showing that a classification system is not a cognitive artefact, applied once as a means of categorisation, but rather that it is a process, which involves decisions made at different stages temporally and by people with different roles and responsibilities. In so doing, it moves away from the argument that classification systems can marginalise people, considering this too simple, to demonstrate how, from the perspective of those for whom the system is intended as a mechanism of inclusion, the multiplicity of judgements made in the process may not lead to a single outcome of marginalisation or inclusion, but to a more complex picture.

\section{Methodology}

The study reported here is part of a larger study of SwD and their learning in an Australian university. The research design involves a mixed method interpretive approach (Veal \& Darcy, 2014), with the data reported here were collected in 2017 in two stages. First, the 1675 students registered with the disability services unit in the university were sent an email from the staff in that unit, inviting them to participate in an online questionnaire. This number comprises $3 \%$ of the student population of the university. Second, students participating in the online questionnaire were asked if they were willing to participate in their choice of a follow-up interview or email response, with a structured interview schedule. The questionnaire was undertaken through the Qualtrics survey platform which has been accredited for its accessibility for people with disabilities and is certified compliant with Section 508 of the US Rehabilitation Act (1973) as amended in 1998. It received 200 valid responses, giving a response rate of $12 \%$. This should be acknowledged as a limitation of the study, but several factors which can lead to this kind of response rate are acknowledged, including the requirement for contacting students 'at arms' length' and by email, as well as the use of the online survey platform which has been recognised as giving an anticipated response rate of between 12 and 15\%. Another factor affecting the response rate is the number of students registered with the disability services unit. This original registration is done at the point of enrolment and many students never have any contact with the unit. 
The questionnaire collected basic demographic data including information about the course the student was studying and the nature of their disability or medical condition. A little over two-thirds of respondents were female (67.8\%), with a little under one third being male $(28.3 \%)$ and the remainder identifying as non-binary $(2.3 \%)$ or preferring not to say $(1.5 \%)$. This distribution was in line with the distribution of students registered with the disability services unit, as was their distribution across faculties and schools. Relevant to this study, students were asked about the nature of the main type of disability or health condition they reported, and the impact disability had on their studies. Mental health, identified by $43.9 \%$ of respondents, was the most commonly noted disability, either on its own or in conjunction with one or more disabilities, followed by a medical condition at $20.2 \%$. A relatively small number (11\%) asserted that their condition was not included in the categorisation used by the university, although all responses could have been included in existing categories, as the following examples show: "scoliosis"; "mental health"; "deaf". A small number of openended questions were also included to allow students to expand on their answers and explain issues they faced in their learning. The second phase of data collection invited those who had responded to the online survey to take part in a follow-up round of data collection, and this comprised 16 face-to-face interviews and 10 interviews completed via email from students who agreed to provide more detail on their experiences, including the impact of their disability on their everyday lives.

Qualtrics software produces descriptive statistics, whereas for the open-ended questions from the questionnaire and for the interview data, thematic analysis was undertaken, using content analysis (Krippendorff, 2004). This analytic approach identified key concepts but at the same time was able to use the language of the students to provide a sense of their lived experience. The ICF, the DDA and the AVCC Guidelines provided a conceptual framework for the interpretation of the findings. Data drawn from an interview or email are identified by the number assigned at the point of data collection; data drawn from the questionnaire have no identifying characteristics. The study was approved by the University Human Research Ethics Committee, who established parameters for the data collection.

\section{Findings}

Student responses indicated that they are aware that a system of classification is at work and that its purpose is to put in place processes that would enable them to complete the requirements of their university courses, given the impact of their disability or impairment on their capacity to study. Their responses also indicate that they were not passive participants in the system, but neither were they fully able to exercise autonomy.

The system might be set up to "categorise and process them", and $59(29.5 \%)$ noted the support that they received from the disability services staff, suggesting a humanising element in the process, which prevented a student from "getting lost in the system" and which gave them an understanding of the system to discuss with academic staff "when you have the guts". However, for some, this was not at all a "tidy" way (cf. Clouder et al., 2016) to manage their individual situations. The reasons for the "untidiness" included: being kept outside the classification scheme; mismatches in perceptions of time; having self-perceptions that did not match the classification scheme; not seeing themselves as belonging within the classificatory framework; and deliberately keeping themselves out of the classification scheme; Each of these themes will now be explored. 


\section{Kept outside the classification}

Most respondents appeared to take for granted the need to provide documentation that supported the claim that they met the criteria for eligibility for accommodations. However, three respondents stated that lack of money prevented them from receiving the necessary documentation: "It's over \$200 for an assessment - that's a lot of money for a student"; "I couldn't afford [the assessment]" with a third suggesting "maybe you could have grants ... for assessment". Another reported being uncomfortable with providing documentation, because it contained "explicit" details.

Academic staff sometimes keep students outside of the classification scheme because, as students occasionally reported, their lecturers and tutors do not always accept the validity of their claim to disability. "Mental illnesses are still seen as 'fake' and 'exaggerated' by some academics. They do not believe that you should be unable to complete tasks unless someone has 'died or is in hospital'; they do not recognise the effects of panic attacks/anxiety attacks, low bouts of depression, etc."

Other students found that the requirements of their course of study meant that their disability was not taken into account: "[The University] does not allow any flexibility with assessments for [field of study deleted]." A few students found that the work practices of the academic staff appeared to keep them outside of the framework, with "the lecturer changing a previous, 'Yup I can do that' to 'Nope, not anymore'", or miscommunication with a lecturer or tutor might lead to a situation where the academic says: "I am doing that thing [providing the accommodation] you wanted, despite you telling me I'm not".

\section{The influence of time}

Time is a significant factor for students in the working of the system. In the ICF, time is related to function and the possibility of any changes in that function. Thus, it assumes a pattern of permanence, of temporariness or of intermittence. But for students, time is rarely seen in this way. Students do not experience the stability assumed to be inherent in the classification scheme. They place significant emphasis on the unexpected and on the sense that the process of demonstrating learning may take longer for SwD. The university has a policy for attendance based on a notion of stability and continuing availability - students are expected to attend $80 \%$ of their classes. Some students may recognise that they can never commit to this level of attendance: "I am unable to ensure I can attend due to my illness." Others have unexpected interruptions to their study: "I had a [...] flare up"; "an exhaserbation [sic] in symptoms"; "I cannot always be in class". Students noted that when they were confronted by an unanticipated change in their condition and needed an intervention to make alterations to the agreed plan, the disability services staff were booked up "weeks in advance" and they often had to wait "three or four weeks" for the necessary appointment.

Some students noted that being able to manage their own time was important, rather than having to be dependent on someone else's time frame. It was "easier to listen to lectures at my own pace". For some students, not being provided with learning materials before the class "was impacting my ability to learn", and when promised materials were provided late, it was 
not possible to "make up the lost time". Academic staff are perceived as not always recognizing that time and effort may be different for $\mathrm{SwD}$, with students reporting that they are considered "lazy" or to have "poor time management skills" because they do not complete work in the same timeframe as other students.

\section{Not matching the classification}

From the questionnaire responses, it was clear that some students did not recognise their condition in the classification scheme. Some 22 students (11\%) ticked "Other", but then gave types of disability already in the list, for example arthritis or lupus which are medical conditions or mild depression which would be included in the category of mental health.

The interview format gave some students the opportunity to indicate that they do not remember how they had originally identified their disability at the point of application to university: "I haven't got a clue. I can't recall at all" (Interview1); "It would be ... I'm just trying to think what it would be" "To be honest, I'm not really sure" (Interview 14). "I cannot precisely recall" (Email 3). Some students wanted to acknowledge more than one disability, but "It's like you can only tick one" (Interview 7). While that may have been the case at the point of application for tertiary study, it is not a requirement of the system in place to seek accommodations. Students frequently stated more than one disability, often as the context in which their learning takes place: "I have mental health and medical". "So, I have ADHD and a combination of anxiety and some pretty intense depressive episodes" (Interview 14); I have [a list of five conditions] (Email, identifier deleted).

Sometimes the student may be very clear on what they identified as their disability in the paperwork to seek accommodations, but actually describe some other conditions that affects their learning: "I chose mental health ... part of the problem is like with my eyes ... that's nothing to do with my mental health ... they [Disability Services] don't know about this" (Interview 10). The need to meet externally imposed criteria may affect the way a student's disability is recorded and reported. Another student was not clear on what had been reported because the documentation is usually prepared by someone else: "There was a document I had to sign, doctors' reports I had to supply and stuff like that" (Interview 16).

\section{Not wanting a place in the classification}

Some students do not want to have to be seen to have a place in the classification scheme, because they see themselves as "normal", although they recognise that they may need accommodations to help them succeed in their studies, as the following three questionnaire responses demonstrate: "I did not want to be labeled disabled when I have a health condition"; "I can and do manage a family, a job, my studies and my mental health condition - I don't need a 'responsible person' to write an impact statement for me"; "It is off putting being labeled as disabled when I do not see myself this way".

Whereas these students agree to be included within the scheme because of the benefits of receiving accommodations, other students frequently keep themselves outside of the classification scheme. Every questionnaire respondent said that there had been times when they had not disclosed their condition and therefore would not receive any accommodation, with $17.5 \%$ reporting that they rarely or never disclose. Although $39 \%$ have on occasion 
disclosed to their lecturers and tutors, only $14.9 \%$ have disclosed to their fellow students. Only $27.4 \%$ sought accommodation in all the subjects they studied, with $22.3 \%$ seeking no accommodation at all. Of those who sought some level of accommodation, $18.9 \%$ indicated that it was sometimes or never satisfactory. Reasons not seeking accommodations included not believing it would help (26.6\%), not knowing they could do so $(12.7 \%)$ and not needing or wanting accommodations (4.4\%). Other reasons for not disclosing, extracted from the questionnaire responses included: "I was afraid of judgement from others"; "I'm embarrassed"; "there is a lot of stigma associated with mental health issues, so I prefer not to make it public knowledge"; "I think my mobility is obvious so there wasn't a need to tell people".

\section{Discussion}

The Disability Discrimination Act 1992 sets the legislative framework within which universities in Australia must operate. This act, which draws on the ICF, is concerned with the notions of equity and fairness. Inherent in it is the assumption that a person with disability is in some way different and that adjustments have to be made for someone to be able to participate "on the same basis". The legislation and the subsequent AVCC Statement relating to SwD assume that all SwD will be covered and that they will be advantaged by the terms of the legislation and the policies and processes enacted in universities. However, the findings of this study indicate that from the actions and experiences reported by students, these assumptions are not evident in the way the classification scheme works.

The classification scheme and the associated processes do not always work, in the ways the DDA and the AVCC Guidelines can be assumed to have intended. Firstly, this is because those who should be included are not always deemed eligible. This occurs in two ways: students are not able to get the documentation to provide evidence of their condition; academic staff may decide not to implement recommendations for action because they do not accept the basis on which the recommendations are made and/or seek specific detail. These academic staff members may be contravening not only the DDA but also, through asking students specific questions about their disability, contravening the Privacy Act, even though their focus may be on the integrity of an academic program. Some students may be denied accommodations because academic staff may determine that the requirements of the learning approach or the requirements of professional accreditation preclude certain accommodations. This action falls within the parameters of the AVCC Guidelines. Secondly, the classification scheme and associated processes does not work because students cause it not to work for them, by withdrawing from the processes through which the classification scheme is put into practice, especially through not disclosing their disability; in this way, they recognise the political aspects inherent in the classification scheme and the associated administrative processes.

The implementation of this classification scheme can and does marginalise students. It does this by seeking to create a simpler means of understanding the complex interactions of a person's disability, their support needs and other aspects of the impairment effects on their embodied selves, and the social context that they are interacting with. Here, some students sought to be accepted as "normal", while at the same time recognising that they would need first to be accepted as having a place in the classification scheme, that is as "not normal" (Campbell, 2012). Others resented the need to be labelled as "not normal" by a representative 
of the medical profession when, by many measures, their lives and the ways they lived them paralleled those of people without disability (Hahn, 1985).

Yet, the responses from these students provide a more nuanced interpretation of the workings of the classification scheme, going beyond medical or administrative considerations. This study has shown that the implementation of a system so that SwD can operate "on the same basis" involves the disability and the students being categorised and processed, as Clouder et al. (2016) noted. It has shown exercises of power in the way this is done (cf Bowker and Star, 1999). The power to exclude is wielded by academic staff in granting or not the accommodations. While this may have been a deliberate exercise of power based on believing the student was involved in some kind of scam, or because a lecturer has a dual responsibility, to support the learner and to maintain the academic integrity of the education program, it also occurred from the human failings of forgetfulness or of shifting priorities, a factor rarely mentioned in other studies.

The marginalising effects of poverty were also apparent in this study, with students identifying that they were unable to pay for the evidence to support their claim of the need for accommodations in their study. This left them outside of the scheme, with no way of entering into the classification, unlike the students in Peruzzo's Italian study, who were expected to demonstrate 'frugality' with an allowance designed to support their inclusion within university support services (2020).

Disparate notions of time also had marginalising effects. The unexpected exacerbation of a condition, or the unforeseen need for hospitalisation, may not match the "cripped time" described by Campbell (2012), with its sense of unpredictability and chaos. Nonetheless, many SwD must manage both the planning and routine that underpins successful study and the unpredictability of their condition within a system that has little flexibility to adapt to the unexpected, given the routinized approach to time inherent in the teaching and learning processes in a university.

Power is frequently taken as the power to exclude (eg Campbell, 2008; Foucault, 1977; Peruzzo, 2020) but in this study, there is significant acknowledgment of the power of the disability services consultants in supporting students in such a way that largely they did not feel that they were being made to fit into a system. The students perceived the person with whom they liaised as someone there to advocate for them, linking the application of the classification scheme to the requirements of a university program of study and devising recommendations for action by the academic staff. Instead of feeling contained within a framework, most felt that they benefited by going through the process; in other words, instead of focussing on the classification scheme and its fit with their circumstances, they focussed on the positive outcomes that engagement with the classification scheme brought them, even when these outcomes could be costly in the "service time" necessary for engagement in the process (Campbell 2012) or in the risk of stigmatisation (cf Grimes et al. 2019).

SwD also exercise power and agency, separating the acceptable from the unacceptable. Some find the stigmatisation that may follow disclosure through the application process unacceptable, and therefore choose not to apply or to apply but not to disclose to the teaching staff (Grimes et al., 2019; Lynch and Gussel, 1996; Matthews, 2009). In doing this, they exercise power over their privacy and over their dignity. They are visible to their lecturers and tutors within their classes, while the disability and its impacts remain invisible. It may 
even be that they become visible as a student who is struggling to succeed in a subject but staying invisible as a SwD may give them a greater sense of control over their identity and a stronger sense of autonomy.

For SwD not to be discriminated against, in the context of the legislation and policy guidelines, their disability must become public, it must be named and labelled and appropriate behaviours for others must be identified. Through this process, it is all too easy for the individual person to disappear behind the label which is, in a societal sense, intended to facilitate their capacity to live "on the same basis". That some students in this study resent the identity thrust on them by this system of classification is understandable. Key to this identity is that they are not "normal" for some period of time and that steps should be taken by those with positions of authority to ensure that arrangements are made, as far as is possible, to normalise them. This public acknowledgement of disability, and the labelling of an individual as being "with disability", separates them from others (Said, 1979), creating their condition as "undesirable" (Foucault, 1977). Labelling runs the risk of simplifying the complexity of the individual in their multi-faceted life into a category with a label attached, such that the complexity disappears.

This study has shown that the processes of categorisation and ordering inherent in the university practices based on the Disability Discrimination Act 1992 are not consistent in their implementation. This is not to imply that the practices of a university discriminate against these students. Rather, it is that students and others in the university system do not share the assumptions that underpin the classifications and definitions in both documents. Some students exercise their power to ensure that they are not subjected to assumptions which they find unacceptable and others exercise their power to remain outside of the system set up to help and support them because they are aware that others will find their situation unacceptable. This can be demonstrated clearly in the following hypothetical scenario, derived from the data.

A young person by the name of A Student is at the end of the third year of an undergraduate degree, studying part time. S/he has a documented medical condition and associated mental health conditions and, in the first two years of study, has registered with the disability services unit in the university and sought accommodations. In third year, s/he took four subjects. Table 1 summarises the decisions $\mathrm{s} / \mathrm{he}$ took and the outcomes of the applications for accommodations within the AVCC Guidelines:

\begin{tabular}{|l|l|l|l|l|}
\hline & Subject 1 & Subject 2 & Subject 3 & Subject 4 \\
\hline $\begin{array}{l}\text { Application for } \\
\text { accommodations }\end{array}$ & YES & YES & YES & NO \\
\hline $\begin{array}{l}\text { Disclosure to } \\
\text { teaching staff }\end{array}$ & YES & NO & NO & N/A \\
\hline $\begin{array}{l}\text { Perspective of } \\
\text { teaching staff }\end{array}$ & $\begin{array}{l}\text { Mental health } \\
\text { claims usually a } \\
\text { fake }\end{array}$ & $\begin{array}{l}\text { Supportive of } \\
\text { requests made } \\
\text { through the } \\
\text { process }\end{array}$ & $\begin{array}{l}\text { Demands of } \\
\text { professional } \\
\text { accreditation } \\
\text { preclude } \\
\text { requested } \\
\text { accommodations }\end{array}$ & N/A \\
\hline Outcome & $\begin{array}{l}\text { Accommodations } \\
\text { denied }\end{array}$ & $\begin{array}{l}\text { Accommodations } \\
\text { granted }\end{array}$ & $\begin{array}{l}\text { Accommodations } \\
\text { denied }\end{array}$ & $\begin{array}{l}\text { No } \\
\text { accommodations }\end{array}$ \\
\hline
\end{tabular}


Through this scenario, it is apparent that the classification system has worked in four different ways for the student. While this lack of consistency may not in itself be new (see for example Treas 2009, p. 73), it does highlight factors that prevent services intended to "promote equal opportunities and participation" (WHO 2013, p. 48) from doing so in a stable and dependable way. Thus, the findings of this study have not demonstrated the consistency implied by Clouder et al.'s notion of "the tidy way" with its sense of regularisation and conformity to a norm (2016). Nor have they shown the existence of a social order that Bowker and Star (2000, p.147) indicate is imposed through a classification scheme. Instead, they have indicated how the concerns of individuals are fundamental to the way that the classification system inherent in the practices designed to support SwD works.

\section{Implications of the study}

The inconsistencies in the workings of a classification system as demonstrated in this study have implications for those legal and administrative instruments, DDA and the AVCC Guidelines, from which it is derived. They are concerned with issues of fairness and equity within an organisational context as well as at a societal level. Issues of fairness and equity may be enshrined in policy statements in organisations. The findings indicate that many students recognise the assumptions inherent in the ICF, the classification scheme that guides the classification of their disability and the understanding of how living with disability may affect everyday living, and they make decisions on how to position themselves within the classification or to stand apart from it, one way or the other to seek to be "normal". These decisions at one level deny them fairness and equity. They may choose not to seek any adjustment and if they do, they may not disclose that they have a disability to the teaching staff. In other words, students in the university will make choices that negatively affect fairness and equity to preserve a sense of self and of autonomy and of power over their situation. They seek to keep private rather than give up anonymity in order to improve their learning or performance outcomes. This in itself is a powerful signifier of the level of stigmatisation felt by some SwD because of the workings of the process which itself is supposed to facilitate participation "on the same basis" and equally a strong signifier of the autonomy exercised by some.

The decisions of academic staff, as reported by students, can also affect issues of fairness and equity. The lack of acknowledgement of the impact of a student's disability by academic staff and the resulting invisibility in the system means that an important mechanism in any administrative process is removed, and that is the complaint mechanism, the ability to call out examples of discrimination (Grimes et al., 2019). Complaints mechanisms are important aspects of the review and evaluation of the effectiveness of any system, and when students or employees with disability remove themselves from the system or fall outside of it, any complaints that might have arisen from their experiences with accommodations can no longer be made, the classification system is not tested and changes are not implemented.

A further implication arises from the suggestion offered by WHO that "service systems" can generate data to guide future decision-making" (WHO 2013, p. 48). Universities use data from student registrations with a disability services unit to report on their performance in meeting targets for equity and diversity. A challenge is for universities to avoid turning a student into a reportable statistic in their quest for a standardised data collection tool with 
which to report on the diversity of the student body, another way in which organisations like universities "tidy up" a disparate and messy workforce or student body.

Finally, the study has implications for information science. It adds to the body of work that demonstrates that a classification system encompasses a theoretical perspective that may not be appropriate for the cultural or social context in which it is applied. It demonstrates, in the context of students with disability, that the meaning inherent in the labelling of this classification system conveys socially unacceptable connotations and further, that the requirements of one person with disability cannot be assumed to be the same for another person, even with the same disability as both the level of their support needs differs as well as the social context that they find themselves interacting with.

A classification system is more than the outcome of the intellectual work of observation and categorisation. It is a process involving people making judgements and decisions on how to interpret the classification scheme. The work that a classification system does depends not only on the intellectual work of those who devised the scheme, but on the strategic organisational decisions of those who develop policies to apply such a scheme and on the everyday decisions of those who implement it. It becomes increasingly important for information scientists to be involved in societal and organisational debates on the consequences of applying classification schemes to people.

\section{Conclusion}

Classification schemes and the work that they do impact on people's everyday lives. While it may be impossible to change classification schemes developed over decades, and which underpin much of the ordering of information in everyday life, there is the opportunity to take the lessons learned from the experiences of SwD in being categorised and processed and apply them more broadly. The act of categorising people will always be fraught with difficulty, but it may be possible to consider developing classifications and ways of implementing them that facilitate a fair and equitable social context. The medical model of loss and deficit, which underpins attempts to put a socio-cultural gloss on policies adopted by many organisations, brings with it a discourse that takes the classification scheme considered here into the everyday language and practices of students and decision-makers, with detrimental consequences for those caught up in the inherent exercises of power.

In adding to the literature on the impact of classification schemes on people in their everyday lives, this study has made three key contributions to the literature of information science. It has brought to light the voices of those subject to the classification system and demonstrated their experiences with it. It has shown that the artefact of a classification scheme is turned into a process when applied in an organisational setting, and that this process can involve multiple decision points leading to inconsistent outcomes. Finally, it has demonstrated that a key tenet of a classification scheme, a decision on categorisation, is not the final word in a societal context; it is the acceptance or rejection of the associated label by any one of the multiple individuals involved at any point in time that is actually the point at which the categorisation is made or disputed.

\section{Acknowledgements}

We thank the staff in the Disability Services unit of the unnamed university, without whose assistance this study would not have been possible, the students who agreed to take part in the 
study. We also thank the anonymous reviewers for their constructive comments and criticisms which have led to a much stronger paper.

\section{References}

Altman, B. (2001), "Disability definitions, models, classification schemes, and applications," in Albredht, G., Seelman, K. and Bury, M. (Eds.), Handbook of Disability Studies, Sage Publications, Thousand Oaks, pp. 97-122.

Australia Disability Discrimination Act (1992), No. 135 of 1992, No. 164 of 2016, available at https://www.legislation.gov.au/Details/C2016C00763 (accessed 25 November 2020)

Australian Bureau of Statistics (2019), 4430.0 - Disability, Ageing and Carers, Australia: Summary of Findings, 2018, available at: https://www.abs.gov.au/AUSSTATS/abs@.nsf/productsbyCatalogue/C258C88A7AA5A87E CA2568A9001393E8? OpenDocument (accessed 25 November 2020)

Australian Network on Disability and Business Council of Australia (2016), Sharing and Monitoring Disability Information in Your Workforce: a Guide for Employers, available at: https://www.and.org.au/data/Info Sharing/Information Sharing Monitoring_PDF.pdf (accessed 25 November 2020)

Australian Vice Chancellors' Committee (2006), Guidelines relating to students with a disability, AVCC, Canberra, available at: https://www.adcet.edu.au/resource/5351/universities-australiaavcc-guidelines-relating-to-students-with-a-disability-2006/ (accessed 25 November 2020)

Barfoed, E.M. (2019), "Digital clients: An example or people production in social work", Social Inclusion, Vol.7, No.1, pp. 196-206.

Beauchamp-Pryor, K. (2012) "From absent to active voices: securing disability equality within higher education", International Journal of Inclusive Education, Vol. 16 No.3, pp 283-295.

Bickenbach, J. E., Chatterji, S., Badley, E. M. and Üstün, T. B. (1999), "Models of disablement, universalism and the international classification of impairments, disabilities and handicaps", Social Science \& Medicine, Vol. 48 No. 9, pp. 1173-1187. doi:10.1016/S02779536(98)00441-9

Blockmans, I. (2015), “'Not wishing to be the white rhino in the crowd': disability-disclosure at university", Journal of Language and Social Psychology, Vol. 34 No. 2, pp. 158-180.

Bowker, G. and Star, S. (1999), Sorting things out: Classification and its Consequences, MIT Press, , Cambridge, Mass.

Bowker, G. and Star, S. (2000), "Invisible mediators of action: Classification and the ubiquity of standards", Mind, Culture and Activity, Vol. 7, Nos. 1-2, pp. 147-163. doi:10.1080/10749039.2000.9677652

Campbell, F.K. (2008), "Exploring internalized ableism using critical race theory", Disability and Society, Vol. 23 No. 2, pp. 151-162.

Campbell, F. K. (2012), "Stalking ableism: using disability to expose 'abled' narcissism", in Goodley, D., Hughes, B. \& Davis, L. (Ed.s.), Disability and Social Theory, Palgrave Macmillan, London, pp. 212-230.

Campbell, F. K. (2019), "Precision ableism: a studies in ableism approach to developing histories of disability and abledment", Rethinking History, Vol. 23 No. 2, pp. 138-156. doi:10.1080/13642529.2019.1607475

Clifton, S. (2020), Hierarchies of Power: Disability theories and models and their implications for violence against, and abuse, neglect, and exploitation of, people with disability. Research Report. Royal Commssion into Violence, Abuse, Neglect and Exploitation of People withDisability. https://disability.royalcommission.gov.au/system/files/202010/Research $\% 20$ Report $\% 20$ \%20Hierarchies\%20of\%20power Disability\%20theories\%20and\%20models\%20and\%20thei r\%20implications\%20for\%20violence\%20against, \%20and\%20abuse, \%20neglect, $\% 20$ and $\% 2$ 0exploitation\%20of,\%20people\%20with\%20disability.pdf (Accessed 10 March 2021).

Clouder, L., Adefila, A., Jacksin, C., Opie, J. and Odedra, S. (2016), "The discourse of disability in higher education: insights from a health and social care perspective", International Journal of Educational Research, Vol. 79, pp. 10-20. 
Cooper, A. (2007), Inventing the indigenous. Local knowledge and natural history in early modern Europe, Cambridge University Press, Cambridge.

Dali, K. (2018), "The lifeways we avoid: The role of information avoidance in discrimination against people with disabilities", Journal of Documentation, Vol. 74 No. 6, pp. 1258-1273. https://doi.org/10.1108/JD-04-2018-0057

Darcy, S. and Buhalis, D. (2011), "Conceptualising disability”, in Buhalis, D. \& Darcy, S. (Ed.s), Accessible Tourism: Concepts and Issues, Channel View Publications, Bristol, pp. 21-45.

Denhart, H. (2008), “Deconstructing barriers", Journal of Learning Disabilities, Vol. 41 No.6, pp. 483-497.

Foucault, M. (1977), Discipline and Punish, Random House, New York.

Fredriksson Franzén, F. (2016), Creating Sustainable Action Nets: The case of ugly vegetables. Master's Thesis, Gotenburg University, Available at: https://gupea.ub.gu.se/handle/2077/47544 (Accessed 10 March 2021.)

Gabel, S. and Miskovic, M. (2014), "Discourse and the containment of disability in higher education: an institutional analysis", Disability and Society, Vol. 29 No. 7, pp. 1145-1158.

Garsten, C. and Jacobsson, K. (2013), "Sorting people in and out: The plasticity of categories of employability, work capacity and disability as technologies of government", ephemera; theory \& politics in organization, Vol. 13, No.4, pp. 825-850.

Grimes, S., Scevak, J., Southgate, E. and Buchanan, R. (2017), "Non-disclosing students with disabilities or learning challenges: Characteristics and size of a hidden population", The Australian Educational Researcher, Vol. 44, no. 4, pp. 425-441

Grimes, S., Southgate, E., Scevak, J. and Buchanan, R. (2019), "University student perspectives on institutional non-disclosure of disability and learning challenges: reasons for staying invisible", International Journal of Inclusive Education, Vol. 23 No. 6, pp. 639-655.

Hahn, H. (1985), "Towards a politics of disability; definitions, disciplines, and policies", available at: https://www.independentliving.org/docs4/hahn2.html (accessed 25 November 2020)

Hajibayova, L. and Buente, W. (2017), "Representation of indigenous cultures: considering the Hawaiian hula", Journal of Documentation, Vol. 73 No. 6, pp. 1137-1148. https://doi.org/10.1108/JD-01-2017-0010

Hammell, K. (2004), "Using qualitative evidence to inform theories of occupation", in Hammell, K. \& Carpenter, C. (Ed.s), Qualitative Research in Evidence-based Rehabilitation, Churchill Livingstone, Edinburgh, pp. 14-26.

Harpur, P. (2012), "From disability to ability: changing the phrasing of the debate", Disability and Society, vol. 27 No. 3, pp. 325-337, DOI: 10.1080/09687599.2012.654985

Heath, D. and Babu, R. (2017), "Theorizing managerial perceptions, enabling IT, and the social inclusion of workers with disabilities", Information and Organization, Vol. 27 No. 4, pp. 211225. doi:10.1016/j.infoandorg.2017.09.001

Hogan, A. (2019), "Moving away from the 'medical model': the development and revision of the World Health Organization's Classification of Disability", Bulletin of the History of Medicine, Vol. 93 No. 2, pp. 241-269.

Holstein, J. (1992), "Producing people: descriptive practices in human service work", Current Research on Occupations and Professions, Vol. 7, pp. 23-29.

Krippendorff, K. (2004), Content Analysis: An Introduction to. its Methodology, (2nd ed.). Sage, Thousand Oaks, CA.

Lane, L. (2014), “Am I being heard?' The 'voice of' students with disability in higher education: A literature review", Paper presented at: Inclusive Higher Education. National and International Perspectives Conference, University of Leipzig, Germany, 22-23 September 2014 Available from:

https://www.researchgate.net/publication/299536558_Am I being_heard' The 'voice_of'st udents with disability in higher education A literature review (Accessed 30 March 2021).

Leonardi, M., Bickenbach, J., Ustun, T. B., Kostanjsek, N. and Chatterji, S. (2006), "The definition of disability: what is in a name?", The Lancet, Vol. 368 No. 9543, pp. 1219-1221.

doi:10.1016/S0140-6736(06)69498-1 
Lynch, R. T. and Gussel, L. (1996), "Disclosure and self-advocacy regarding disability-related needs: strategies to maximize integration in postsecondary education", Journal of Counseling \& Development, Vol. 74 No. 4, pp. 352-357. doi:10.1002/j.1556-6676.1996.tb01879.x

Mai, J-E. (2010), "Classification in a Social World: Bias and Trust," Journal of Documentation, Vol. 66, No. 5 pp. 627-42, https://doi.org/10.1108/00220411011066763;

Mai, J-E. (2011), “The modernity of classification”, Journal of Documentation, Vol. 67 No. 4, pp. 710-730.

Matthews, N. (2009), "Teaching the 'invisible' disabled students in the classroom: disclosure, inclusion and the social model of disability", Teaching in Higher Education, Vol. 14 No. 3, pp. 229-239. doi:10.1080/13562510902898809

Olson, H. (2010), "Social Influences on Classification", in Bates, M. and Maack, M. (Eds.) Encyclopedia of Library and Information Sciences, 3rd ed., Taylor and Francis, New York, pp. 4806-13.

Peruzzo, F. (2020), "The Model of Becoming Aware: disabled subjectivities, policy enactment and new exclusions in higher education", Journal of Education Policy, DOI: 10.1080/02680939.2020.1856415 (Accessed 30 March 2021).

Said, E. (1979), Orientalism, Routledge, London.

Simmeonsson, R., Lollar, D., Björck-Åkesson, E., Granlund, M., Brown, S., Qiu, Z., Gray D. and Pan, Y. (2014), "ICF and ICF-CY lessons learned: Pandora's box of personal factors", Disability and Rehabilitation, Vol. 36 No. 25, pp. 2187-2194.

Treas, J. (2009), "Age in standards and standards for age: institutionalizing chronological age as biographical necessity", in Lampland, M. and Star, S.L (Eds.) How Quantifying, Classifying and Formalizing Practices Shape Everyday Life, Cornell University Press, Ithaca, pp. 65-94.

United Nations (2006), Convention on the Rights of Persons with Disabilities available at https://treaties.un.org/Pages/ViewDetails.aspx?src=TREATY\&mtdsg no=IV$15 \&$ chapter $=4 \&$ clang $=$ en $($ accessed 25 November 2020).

Veal, A.J., and Darcy, S. (2014), Research Methods in Sports Studies and Sports Management, Routledge, Milton Park UK.

Waddington, L. and Priestley, M. (2021), "A human rights approach to disability assessment", Journal of International and Comparative Social Policy, Vol.37 No.1, pp. 1-15.

Wiegand, W. A. 1996, Irrepressible Reformer: A Biography of Melvil Dewey, American Library Association, Chicago.

World Health Organization (1980), International Classification of Impairments, Disabilities and Handicaps $(I C I D H)$, World Health Organization, Geneva, available at: https://apps.who.int/iris/bitstream/handle/10665/41003/9241541261 eng.pdf?sequence=1\&ua $=1$ (accessed 25 November 2020)

World Health Organization (2001), International Classification of Functioning, Disability and Health $(I C I D H-2)$, World Health Organization, Geneva, available at: https://www.who.int/classifications/international-classification-of-functioning-disability-andhealth (acessed on 25 November 2020).

World Health Organization (2002), Towards a Common Language for Functioning, Disability and Health - ICF, World Health Organization, Geneva, available at: https://www.who.int/classifications/icf/icfbeginnersguide.pdf (accessed 25 November 2020).

World Health Organization (2013), How to use the ICF; A Practical Manual for Using the International Classification of Functioning, Disability and Health, Exposure draft for comment, October 2013, World Health Organization, Geneva. https://www.who.int/classifications/drafticfpracticalmanual.pdf (Accessed 10 March 2021)

\section{Funding}

This work was supported by the Disability Project Fund of [name removed] university. 